\title{
Técnicas e Medidas em Orientação Profissional e de Carreira: Resenha do Livro
}

\author{
Fabiola Rodrigues Matos ${ }^{1}$ \\ Fernanda Mendes Pires ${ }^{1}$ \\ ${ }^{1}$ Universidade Federal do Espirito Santo, Vitória, Espirito Santo, Brasil
}

Intervenções no domínio da orientação profissional e de carreira configuram-se como possibilidades adequadas para o auxílio de jovens e adultos nas transições educacionais e ocupacionais, considerando as diversas configurações do trabalho na contemporaneidade (Agibo \& Melo-Silva, 2018). Nesse contexto, situa-se o livro "Técnicas e Medidas em Orientação Profissional e de Carreira", lançado em 2019, pela Editora Vetor e organizado por quatro professores e pesquisadores brasileiros: Alexsandro Luiz de Andrade, Maiana Farias Oliveira Nunes, Manoela Ziebell de Oliveira e Rodolfo Augusto Matteo Ambiel. O livro apresenta técnicas criadas ou adaptadas para o uso no contexto brasileiro na prática de Orientação Profissional e de Carreira. Objetiva-se, por meio desta resenha, apresentar uma síntese do livro cuja proposta é fornecer ferramentas que priorizam o desenvolvimento do comportamento exploratório voltado ao mundo do trabalho.

A primeira parte do livro traz técnicas para orientação profissional e desenvolvimento de carreira, com dois capítulos que abordam o planejamento e gerenciamento de carreira, respectivamente. No primeiro capítulo, de Alexsandro Luiz de Andrade, Juliana Pereira Rodrigues, Juliana Nascimento Lucas Ramalhete e Luiz Henrique Lorenzoni Cibien, são apresentadas duas técnicas para orientação profissional: o currículo futuro e o mapa das oportunidades. Essas técnicas qualitativas propõem reflexões quanto à construção de seu futuro profissional e o mapeamento geral de aspectos mercadológicos, competências e requisitos para investidura no projeto profissional.

Em um contexto similar, o segundo capítulo, de Ligia Carolina Oliveira-Silva e Bruner de Morais Miranda, disponibilizam a técnica do mapa de oportunidades para estimular a reflexão sobre características pessoais, planos e possibilidades realistas de carreira, além de permitir que as etapas do processo sejam sintetizadas em um documento escrito que representa o produto de orientação de carreira. Em ambos os capítulos há a apresentação de um exemplo da utilização da técnica e sua repercussão no caso específico.

A segunda parte do livro, composta por oito capítulos, traz instrumentos complementares e de pesquisa que proporcionam contribuições singulares ao processo de orientação profissional e de carreira. No capítulo 3, de Bárbara Cristina dos Santos Marques, Marina Cardoso de Oliveira e Lucy Leal Melo-Silva, há a adaptação transcultural da Escala de Engajamento com a Carreira (EEC), que visa avaliar o nível em que o indivíduo está proativamente engajado em comportamentos úteis para o desenvolvimento e a construção de carreira.

Também no contexto de orientação de carreira, tem-se, no capítulo 4, a Escala de Avaliação dos Tipos Profissionais de Holland (ATPH). Esta aborda seis tipos de personalidades vocacionais de acordo com o modelo de Holland, discorrendo sobre como as características pessoais e ambientais influenciam positiva ou negativamente nas escolhas profissionais. Esse capítulo, escrito por Carmélia Murgo Mansão, Maiana Farias Oliveira Nunes, Ana Paula Porto Noronha, Ricardo Primi e Monalisa Muniz, fornece contribuições para a área uma vez que auxilia na compreensão abrangente dos interesses profissionais.

Rodolfo Augusto Matteo Ambiel e Gustavo Henrique Martins, no capítulo 5, desenvolvem a Escala de Interesses por Área da Psicologia (EIAPsi), focada para a área supramencionada e que avalia interesses de estudante pelas áreas da profissão. Dispõe, em sua estruturação, de onze áreas de atuação, proporcionando autoconhecimento e maior entendimento ao graduando sobre as possibilidades de exercício laboral.

Por outro lado, tendo em vista a influência parental no desenvolvimento de carreira dos filhos e que, por exemplo, o suporte parental está associado à autoeficácia para decisão de carreira (Rodrigues, Gamboa, Vieira, Paixão, \& Domingues, 2017), Tiago Fernandes Oliveira, Marúcia Patta Bardagi e Vítor Gamboa trazem um estudo preliminar sobre a utilização da Escala de Suporte Parental para o Desenvolvimento de Carreira no contexto do brasileiro no capítulo 6 . O referido instrumento tem base na Teoria Social Cognitiva, com o objetivo de avaliar a percepção de adolescentes acerca do suporte percebido em relação ao desenvolvimento de carreira.

$\mathrm{Na}$ mesma perspectiva teórica, porém focada em atividades ocupacionais, está a Escala de Autoeficácia 
para Atividades Ocupacionais (EAAOc) de Maiana Farias Oliveira Nunes, Ana Paula Porto Noronha e Jeferson Gervasio Pires, no capítulo 7. Esse instrumento preconiza a existência da relação entre características pessoais e ambientes de trabalho. Assim sendo, avalia a autoeficácia para atividades ocupacionais considerando-a para a tipologia de Holland.

Alexsandro Luiz de Andrade, no capítulo 8, apresenta o papel dos padrões de apego no contexto de relações interpessoais no trabalho e desenvolve a Escala de Apego Adulto em Relações de Trabalho (EAT-12). A análise de características de apego nesse ambiente pode favorecer melhor conhecimento de aspectos da personalidade, desenvolvimento e planejamento de carreira, bem como auxiliar em estratégias para aprimoramento pessoal. $\mathrm{O}$ instrumento é indicado para indivíduos que tenham algum tipo de experiência profissional, ao menos escolaridade de ensino médio, além de boa compreensão de leitura escrita e verbal.

Considerando as novas configurações das carreiras na atualidade, o capítulo 9 disponibiliza um instrumento que visa avaliar as prioridades nas tomadas de decisão de carreira. Patrícia Bock Bandeira, Alexsandro Luiz de Andrade e Manoela Ziebell de Oliveira trazem a adaptação da Escala de Parâmetros da Carreira Caleidoscópica (EPCC), verificando a tendência do indivíduo quanto aos aspectos de autenticidade, balanço e crescimento. $\mathrm{O}$ uso dessa escala é relevante por mensurar os pressupostos do modelo de carreira contemporânea que leva em consideração o contexto de vida dos profissionais e seu protagonismo na tomada de decisão de carreira. Dessa maneira, possibilita melhor compreensão e análise das trajetórias profissionais dos indivíduos de forma dinâmica e em consonância com sua história de vida.

Por fim, no último capítulo, de Fernanda Aguillera, Lucy Leal Melo-Silva e Maria Odilia Teixeira, traz o Questionário de Educação para a Carreira (QEC) que auxilia o orientador a planejar ações, bem como a verificar os efeitos e resultados das intervenções. O QEC proporciona tarefas inerentes ao desenvolvimento de carreira e permite identificar necessidades ao priorizar na intervenção da educação para a carreira. É uma escala desenvolvida para estudantes do ensino médio, para uso em adolescentes e jovens.

A obra fornece uma amplitude de uso de técnicas e instrumentos para a área de orientação profissional e de carreira. Os capítulos tratam de conceitos e processos que auxiliam no enfrentamento de possíveis mudanças relacionadas à carreira. Destaca-se que há a presença, em toda a estruturação do livro, de apresentação do referencial teórico, população-alvo, descrição da técnica, dos materiais necessários para sua aplicação, orientação para o uso, interpretação e discussão do conteúdo. A partir disso, do ponto de vista prático, é uma leitura adequada e útil para pesquisadores e orientadores profissionais e de carreira que buscam instrumentos com boas características psicométricas.

\section{Referências}

Agibo, M. L. L. C., Melo-Silva, L. L. (2018). Orientação profissional e de carreira na perspectiva de adolescentes moçambicanos. Revista da SPAGESP, 19(2), 49-63. Recuperado de https://dialnet.unirioja.es/ servlet $/$ articulo?codigo $=6854186$

Andrade, A. L. de, Nunes, M. F. O., Oliveira, M. Z. de, \& Ambiel, R. A. M. (2019). Técnicas e medidas em orientação profissional e de carreira. São Paulo: Vetor Editora.

Rodrigues, S., Gamboa, V., Vieira, L. S., Paixão, O., \& Domingues, D. (2017). Suporte parental e autonomia: Efeitos na exploração e na decisão vocacional. Omnia, 7, 41-57. doi: 10.23882/OM07-2017-10-04

Recebido em: 13/12/2019

Reformulado em: $17 / 05 / 2020$

Aprovado em: 29/05/2020 
Sobre as autoras:

Fabíola Rodrigues Matos é psicóloga, docente, mestre em processos cognitivos pela Universidade Federal de Uberlândia e doutoranda em processos psicossociais pela Universidade Federal do Espírito Santo.

ORCID: https://orcid.org/0000-0002-2828-2869

E-mail: fabiolarmatos@yahoo.com.br.

Fernanda Mendes Pires é doutoranda em Psicologia pela Universidade Federal do Espírito Santo, mestre em Administração de Empresas pela Universidade de São Paulo e graduada em Administração pela Universidade Federal do Espírito Santo. Atuação profissional em gestão estratégica de pessoas, desempenho, cultura e clima organizacional. Pesquisa acadêmica atual sustentada pela Psicologia do Trabalhar, uma perspectiva inclusiva da orientação profissional de carreira.

ORCID: https://orcid.org/0000-0002-1964-5357

E-mail:fermpires@gmail.com.

Contato com as autoras:

Prédio Professor Lídio de Souza

Av. Fernando Ferrari, 514, Goiabeiras

Vitória-ES, Brasil

CEP: 29075-910. 